\title{
Nitrogen-Doped Hollow Carbon Spheres with Embedded Co Nanoparticles as Active Non-Noble-Metal Electrocatalysts for the Oxygen Reduction Reaction
}

\author{
Ruohao Xing ${ }^{1,2}$, Yao Zhou ${ }^{1}$, Ruguang Ma ${ }^{1, *}$, Qian Liu ${ }^{1,3, *}$, Jun Luo ${ }^{2,3}$, Minghui Yang ${ }^{4, *}$ and \\ Jiacheng Wang ${ }^{1,3, *}$ \\ 1 State Key Laboratory of High Performance Ceramics and Superfine Microstructure, \\ Shanghai Institute of Ceramics, Chinese Academy of Sciences, 1295 Dingxi Road, Shanghai 200050, China; \\ xingruohao@126.com (R.X.); zhouyao87@mail.sic.ac.cn (Y.Z.) \\ 2 School of Materials Science and Engineering, Shanghai University, 99 Shangda Road, Shanghai 200444, \\ China; junluo@shu.edu.cn \\ 3 Shanghai Institute of Materials Genome, Shanghai 200050, China \\ 4 Ningbo Institute of Materials Technology and Engineering, Chinese Academy of Sciences, Ningbo 315201, China \\ * Correspondence: maruguang@mail.sic.ac.cn (R.M.); qianliu@mail.sic.ac.cn (Q.L.); myang@nimte.ac.cn \\ (M.Y.); jiacheng.wang@mail.sic.ac.cn (J.W.); Tel.: +86-021-5241-2404 (R.M.); +86-021-5241-2413 (Q.L.); \\ +86-0574-8760-8176 (M.Y.); +86-021-5241-2714 (J.W.)
}

Received: 8 January 2018; Accepted: 6 February 2018; Published: 9 February 2018

\begin{abstract}
Transition metal (Fe, $\mathrm{Co}, \mathrm{Ni})$ complexes on carbon nanomaterials are promising candidates as electrocatalysts towards the oxygen reduction reaction (ORR). In this paper, nitrogen-doped hollow carbon spheres with embedded Co nanoparticles were successfully prepared via a controllable synthesis strategy. The morphology characterization shows that the hollow carbon spheres possess an average diameter of $\sim 150 \mathrm{~nm}$ with a narrow size distribution and a shell thickness of $\sim 14.5 \mathrm{~nm}$. The content of $\mathrm{N}$ doping ranges from 2.1 to 6.6 at.\% depending on the calcination temperature from 900 to $1050^{\circ} \mathrm{C}$. Compared with commercial $\mathrm{Pt} / \mathrm{C}$, the Co-containing nitrogen-doped hollow carbon spheres prepared at $900{ }^{\circ} \mathrm{C}$ (CoNHCS-900) as an ORR electrocatalyst shows a half-wave potential shift of only $\Delta \mathrm{E}_{1 / 2}=55 \mathrm{mV}$, but a superior stability of about $90.2 \%$ maintenance after 20,000 s in the $\mathrm{O}_{2}$-saturated $0.1 \mathrm{M} \mathrm{KOH}$ at a rotating speed of $1600 \mathrm{rpm}$. This could be ascribed to the synergistic effects of N-containing moieties, $\mathrm{Co}-\mathrm{N}_{\mathrm{x}}$ species, and Co nanoparticles, which significantly increase the density of active sites and promote the charge transfer during the ORR process.
\end{abstract}

Keywords: cobalt nanoparticles; hollow carbon spheres; fuel cells; electrocatalysis; oxygen reduction reaction

\section{Introduction}

In recent years, fuel cells have been attracting lots of attention due to their high energy conversion efficiency for converting chemical energy into electricity [1-5]. The entire reaction process occurring in fuel cells contains two half-reactions; one is the oxygen reduction reaction (ORR) at the cathode and the other is the hydrogen oxidation reaction (HOR) taking place at the anode. The energy transfer at fuel cells, however, is restricted by the intrinsically sluggish kinetics of ORR [6,7]. Although many catalysts such as $\mathrm{Pt} / \mathrm{C}$ and $\mathrm{Pt}$ alloys are traditionally used to improve the reaction efficiency, the large-scale practical application of them is still difficult due to their high cost, low durability, and scarcity. In order to solve these problems, heteroatom-doped carbon catalysts used in the ORR process have been developed in recent years [8-12]. Nitrogen doping has been extensively studied for its similar size to carbon, while the $\mathrm{N}$ atom has one electron more than carbon in the external shell $[13,14]$. 
Recent studies have shown that heteroatom-doped carbon-based nanomaterials exhibit a good stability, and are low-cost alternatives to commercial Pt/C [14-17]. Meanwhile, transition metals have received intensive attention, mainly owing to their ability to modify the electronic properties of the surface carbon layer [18-22]. With a large number of papers emerging on transition metal-based carbon materials, there are two types of notions about active sites. Some have argued that the metal center is good for the ORR, while others have shown the significance of the transition metal nanoparticles, besides the $\mathrm{M}-\mathrm{N}_{\mathrm{x}}$, to the ORR $[23,24]$.

Co-based composites have been studied as oxygen evolution reaction (OER) or ORR electrocatalysts due to their high catalytic efficiency $[25,26]$. However, Co-based catalysts have mostly been used for OER and showed limited electrocatalytic activities compared with noble metal-based catalysts in alkaline solution for ORR. For example, Lee et al. described the synthesis of nitrogen-doped hollow carbon spheres to encapsulate mixed cobalt-nitride (Co-N) and cobalt-oxide (Co-O) nanosized species, which shows enhanced bifunctional oxygen electrochemical activity [27]. Moreover, cobalt-nitride nanoparticles have been prepared within nitrogen-doped carbon spheres [28], which were studied as the ORR electrocatalysts in basic solution.

Herein, we present a successful synthesis of cobalt nanoparticles and $\mathrm{Co}-\mathrm{N}_{\mathrm{x}}$ species within nitrogen-doped hollow carbon spheres using a soft template method, ammonia decomposition, and impregnation method. In the experiment, PEO-PPO-PEO triblock copolymers (P123) and sodium oleate (SO) were used as a double surfactants soft template, while 2,4-dihydroxybenzoic acid (DA) and hexamethylentetramine (HMT) served as the carbon sources. The $\mathrm{N}$ was doped by the decomposition of ammonia at a high temperature and Co was subsequently anchored on the nitrogen-doped hollow carbon spheres. The catalysts were obtained by carbonization at different temperatures. These Co-embedded NHCSs were also measured as the cathode catalysts in an alkaline environment. The reaction mechanism and active sites were also explored and discussed.

\section{Experiment Section}

\subsection{Reagents}

Potassium thiocyanate $(\mathrm{KSCN})$, cobalt(II) chloride hexahydrate $\left(\mathrm{CoCl}_{2} \cdot 6 \mathrm{H}_{2} \mathrm{O}\right)$, 2,4-dihydroxybenzoic acid (DA), hexamethylentetramine (HMT), potassium hydroxide $(\mathrm{KOH})$, sodium oleate $(\mathrm{SO})$, anhydrous ethanol $(\mathrm{EtOH})$, methanol $\left(\mathrm{CH}_{3} \mathrm{OH}\right)$, and ammonia $\left(\mathrm{NH}_{3}\right)$ were purchased from Sinopharm Chemic Reagent Co. Ltd. (Shanghai, China) Nafion solution (5 wt $\%$ ) and the PEO-PPO-PEO triblock copolymers P123 $\left(\mathrm{EO}_{20} \mathrm{PO}_{70} \mathrm{EO}_{20}, \mathrm{M}_{\mathrm{W}}=5800\right)$ were obtained from Aldrich. The commercial $\mathrm{Pt} / \mathrm{C}$ catalyst (20 wt $\%$ ) was purchased from Johnson Matthey (London, UK). Ultrapure water was used during the synthesis, either.

\subsection{Sample Preparation}

Synthesis of hollow polymer spheres (HPSs). The synthesis of HPSs is referred to in the previous study about hydrothermal polymerization [29-31]. Double surfactants (P123 and SO) were the soft templates, which can react with each other to form the mixture micelle because of the hydrophobic interaction. DA and HMT were the carbon sources. Firstly, DA $(2.4 \mathrm{mmol})$ and HMT $(2 \mathrm{mmol})$ were added in the deionized water $(120 \mathrm{~mL})$ with vigorous stirring for about $10 \mathrm{~min}$ until they had dissolved as solution 'A'. Afterwards, the solution 'B' that contained SO (0.48 mmol) and P123 (0.015 mmol) with deionized water $(40 \mathrm{~mL})$, was slowly poured into solution A. The mixture turned from hyaline to milk white under vigorous stirring for $10 \mathrm{~min}$ to homogenize the solution. Then, the mixed solution was transferred to a Teflon-lined stainless-steel autoclave $(200 \mathrm{~mL})$. The autoclave was sealed and heated at $160{ }^{\circ} \mathrm{C}$ for $8 \mathrm{~h}$. After cooling, the resulting precipitates were collected by centrifugation and washed with deionized water several times. The solid was ground to powder after drying at $80{ }^{\circ} \mathrm{C}$ under vacuum overnight. 
Preparation of nitrogen-doped hollow carbon spheres (NHCSs). The HPSs were thermally treated at $650{ }^{\circ} \mathrm{C}$ for $3 \mathrm{~h}$ with a heating rate of $2{ }^{\circ} \mathrm{C} \mathrm{min}^{-1}$ in $\mathrm{NH}_{3}$ atmosphere at a gas flow rate of $40 \mathrm{sccm}$ to obtain NHCSs.

Preparation of Co-containing nitrogen-doped hollow carbon sphere (CoNHCS). The calculated $\mathrm{CoCl}_{2} \cdot 6 \mathrm{H}_{2} \mathrm{O}$ was dissolved into EtOH and then the NHCSs were dispersed into this solution under magnetic stirring for $30 \mathrm{~min}$ at $80{ }^{\circ} \mathrm{C}$. The doping content of Co in CoNHCSs was $2 \mathrm{wt} \%$. After the evaporation of $\mathrm{EtOH}$, the arid mixtures were then heated at 750,900 , or $1050{ }^{\circ} \mathrm{C}$ in $\mathrm{Ar}$ for $3 \mathrm{~h}$, respectively. The samples were accordingly named CoNHCS-750, CoNHCS-900, and CoNHCS-1050.

Preparation of control samples. To study the effect of $\mathrm{N}$, the control sample without $\mathrm{N}$ doping was also prepared. The carbonization of HPSs was conducted in Ar at $650{ }^{\circ} \mathrm{C}$ for $3 \mathrm{~h}$ with a heating rate of $2{ }^{\circ} \mathrm{C} \mathrm{min}-1$ and the resulting material was named as hollow carbon spheres (HCSs). Then, the HCSs were mixed with the $\mathrm{CoCl}_{2} \cdot 6 \mathrm{H}_{2} \mathrm{O}$ by using the same ratio and procedure. Finally, the mixture was heated at $900{ }^{\circ} \mathrm{C}$, named Co-containing hollow carbon spheres (CoHCS-900).

\subsection{Characterization}

The morphology of the samples was carried out with a field emission scanning electron microscope (FESEM, FEI Magellan 400, Hillsboro, OR, USA) and the microstructure was characterized using transmission electron microscopy (TEM, JEM-2100F, Tokyo, Japan). Raman spectra were obtained on a DXR Raman Microscope (Thermal Scientific Co., Waltham, MA, USA) with a $532 \mathrm{~nm}$ excitation length. The specific surface area and the pore structure of the samples were analyzed by nitrogen adsorption-desorption isotherms measured at 77K (Micrometitics, Norcross, GA, USA). The specific surface areas were calculated with the Brunauer-Emmett-Teller (BET) method. The Pore size distributions were calculated using the Barrett-Joyner-Halenda (BJH) model from the adsorption branch. The total pore volume was ascertained from the amount of nitrogen adsorbed at a relative pressure of 0.99 . The samples were treated at $300{ }^{\circ} \mathrm{C}$ overnight under vacuum during the measuring procedure. X-ray photoelectron spectroscopy (XPS) measurements were performed on an ESCALAB $250 \mathrm{X}$-ray photoelectron spectrometer using $\mathrm{Al} \mathrm{K} \alpha$ source $\left(\mathrm{h}_{v}=1486.6 \mathrm{eV}\right)$ radiation to analyze the surface of the samples. X-ray diffraction (XRD) was carried out on a D8 ADVANCE diffractometer at $40 \mathrm{kV}$ and $100 \mathrm{~mA}$ with $\mathrm{Cu}-\mathrm{K} \alpha$ radiation to determine the phase and crystal structure of the samples. The diffraction angle ranged from $10^{\circ}$ to $80^{\circ}$ at a rate of $2^{\circ} \mathrm{min}^{-1}$.

\subsection{Electrode Preparation and Electrochemical Measurements}

Catalyst inks for the test were prepared by mixing $5 \mathrm{mg}$ of catalyst, $500 \mu \mathrm{L}$ of $\mathrm{EtOH}, 500 \mu \mathrm{L}$ of deionized water, and $30 \mu \mathrm{L}$ of Nafion solution ( $5 \mathrm{wt} \%$, Sigma-Aldrich, St. Louis, MO, USA), followed by ultrasonication for $2 \mathrm{~h}$. The Pt/C catalyst $(20 \mathrm{wt} \% \mathrm{Pt}$ on carbon, Sigma-Aldrich, St. Louis, MO, USA) ink was prepared in the same way for comparison. Afterwards, the ink $(20 \mu \mathrm{L})$ was dropped on the working electrode disk ( $5 \mathrm{~mm}$ diameter, $0.19625 \mathrm{~cm}^{2}$ of geometric surface area) by a micro injector and it was dried to form a film at $50{ }^{\circ} \mathrm{C}$ for $10 \mathrm{~min}$.

The electrocatalytic activity of the samples was tested using a three-electrode system in the $0.1 \mathrm{M}$ $\mathrm{KOH}$ aqueous solution by using an electrochemical workstation (Pine Instrument Co., Grove City, Puerto Armuelles). A saturated calomel electrode (SCE) and a Pt plate were used as the reference electrode and the counter electrode, respectively. The potentials of all the electrochemical test results were transferred to the reversible hydrogen electrode (RHE). The relationship between E(vs. RHE) and $\mathrm{E}(\mathrm{vs} . \mathrm{SCE})$ is shown as follows:

$$
\mathrm{E}(\mathrm{vs} . \mathrm{RHE})=\mathrm{E}(\mathrm{vs} . \mathrm{SCE})+\mathrm{E}_{\mathrm{SCE}}+0.0591 \mathrm{pH}
$$

where the $\mathrm{E}_{\mathrm{SCE}}$ at $25^{\circ} \mathrm{C}$ is 0.2415 and the $\mathrm{pH}$ of $0.1 \mathrm{M} \mathrm{KOH}$ is considered as 13 .

Cyclic voltammetry (CV) or linear sweep voltammetry (LSV) measurements were carried out with a rotating disk electrode (RDE), and a rotating ring disk electrode (RRDE) was used as the working 
electrode for dual-electrode CV measurements. The electrolyte was purged with high-purity bubbling $\mathrm{N}_{2}$ or $\mathrm{O}_{2}$ for at least $0.5 \mathrm{~h}$ before the test and all the experiments were carried at $25^{\circ} \mathrm{C}$. Before each test, a CV with a scanning rate of $200 \mathrm{mV} \mathrm{s}^{-1}$ was first collected to determine the non-Faradaic current.

For the RDE test, a cyclic voltammetry (CV) measurement was conducted from -0.1 to $1.2 \mathrm{~V}$ (vs. $\mathrm{RHE}$ ) in $\mathrm{O}_{2}$-saturated in $0.1 \mathrm{M} \mathrm{KOH}$ solution with a sweep rate of $200 \mathrm{mV} \mathrm{s}{ }^{-1}$ for 50 cycles for the activating electrode. Then, it was performed with $10 \mathrm{mV} \mathrm{s}^{-1}$ for three cycles for data recording. Linear sweep voltammetry (LSV) measurements were performed in $\mathrm{O}_{2}$-saturated $0.1 \mathrm{M} \mathrm{KOH}$ by sweeping the potential from 0.2 to $0.8 \mathrm{~V}$ (vs. RHE) at a rate of $10 \mathrm{mV} \mathrm{s}^{-1}$ with different rotating speeds from 400 to $2025 \mathrm{rpm}$.

The electron transfer number (n) was calculated according to Kouteky-Levich (K-L) Equations (2) and (3), as follows:

$$
\begin{gathered}
\frac{1}{\mathrm{~J}}=\frac{1}{\mathrm{~J}_{\mathrm{k}}}+\frac{1}{\mathrm{~B} \omega^{1 / 2}} \\
\mathrm{~B}=0.2 \mathrm{nFC}_{\mathrm{O}_{2}} \mathrm{D}_{\mathrm{O}_{2}}^{2 / 3} v^{-1 / 6}
\end{gathered}
$$

where $\mathrm{J}$ is the measured current density, $\mathrm{J}_{\mathrm{k}}$ is the kinetic limiting current density, $\omega$ is the electrode rotating rate, $\mathrm{n}$ is the electron transfer number, $\mathrm{F}$ is the Faraday constant $\left(\mathrm{F}=96,485 \mathrm{C} \mathrm{mol}^{-1}\right), \mathrm{C}_{\mathrm{O}_{2}}$ is the bulk concentration of $\mathrm{O}_{2}$ for $0.1 \mathrm{M} \mathrm{KOH}\left(\mathrm{C}_{\mathrm{O}_{2}}=1.2 \times 10^{-6} \mathrm{~mol} \mathrm{~cm}{ }^{-3}\right), \mathrm{D}_{\mathrm{O}_{2}}$ is the diffusion coefficient of $\mathrm{O}_{2}$ for $0.1 \mathrm{M} \mathrm{KOH}\left(\mathrm{D}_{\mathrm{O}_{2}}=1.9 \times 10^{-5} \mathrm{~cm}^{2} \mathrm{~s}^{-1}\right)$, and $v$ is the kinetic viscosity $\left(v=0.01 \mathrm{~cm}^{2} \mathrm{~s}^{-1}\right)$.

In the case of RRDE, a catalyst-coated glassy carbon (GC) disk $\left(0.2475 \mathrm{~cm}^{2}\right)$ surrounded by a Pt ring $\left(0.1866 \mathrm{~cm}^{2}\right)$ was used as a working electrode. The ring potential was held at $1.2 \mathrm{~V}$ (vs. RHE) with a rotating speed of $1600 \mathrm{rpm}$ at the scanning rate of $10 \mathrm{mV} \mathrm{s}^{-1}$. The ring current and disk current were collected from the GC disk and $\mathrm{Pt}$ ring in $\mathrm{O}_{2}$-saturated $0.1 \mathrm{M} \mathrm{KOH}$, respectively. The apparent number of electrons transferred $(n)$ and the percentage of $\mathrm{H}_{2} \mathrm{O}_{2}$ released $\left(\% \mathrm{H}_{2} \mathrm{O}_{2}\right)$ during the ORR process were calculated according to the following equations:

$$
\begin{aligned}
\mathrm{n} & =4 \frac{\mathrm{I}_{\mathrm{d}}}{\mathrm{I}_{\mathrm{d}}+\mathrm{I}_{\mathrm{r}} / \mathrm{N}} \\
\% \mathrm{H}_{2} \mathrm{O}_{2} & =200 \times \frac{\mathrm{I}_{\mathrm{r}} / \mathrm{N}}{\mathrm{I}_{\mathrm{d}}+\mathrm{I}_{\mathrm{r}} / \mathrm{N}}
\end{aligned}
$$

where $I_{d}$ is the disk current, $I_{r}$ is the ring current, and $N$ is the collection efficiency of the Pt ring electrode $(\mathrm{N}=0.37)$.

\section{Results and Discussion}

The SEM images in Figure 1 demonstrate the morphology of the as-prepared samples. Figure 1a,c,e are the back-scattering electron images of CoNHCS-750, CoNHCS-900, and CoNHCS-1050, in sequence. The well-distributed white dots in the images are attributed to Co particles, because the $\mathrm{Co}^{2+}$ was reduced to Co by carbon materials in the heating process. Meanwhile, at high temperature, the resultant Co nanoparticles penetrated into the inside of the NHCSs from the surface. Correspondingly, Figure $1 b, d, f$ show the uniform morphology of the carbon spheres, with a diameter from 130 to $180 \mathrm{~nm}$. The marked sites by red circles are the Co particles, agreeing well with the bright spots in the back-scatting images. TEM images of CoNHCS-900 (Figure S1) further confirm the morphology of the as-prepared samples. Namely, the Co nanoparticles embedded into the hollow carbon spheres, while the carbon spheres with a diameter of about $140 \mathrm{~nm}$ show a shell thickness of $14.5 \mathrm{~nm}$. The particle size distributions of all the samples synthesized at different conditions are summarized in Figure S2. Most carbon spheres counted from the SEM images were in the range of 130 to $180 \mathrm{~nm}$, resulting in an average diameter of $\sim 150 \mathrm{~nm}$. The unique hollow structure with Co nanoparticles and $\mathrm{N}$ doping could be favorable for improving the catalytic activity owing to the increased mass transfer [32]. 


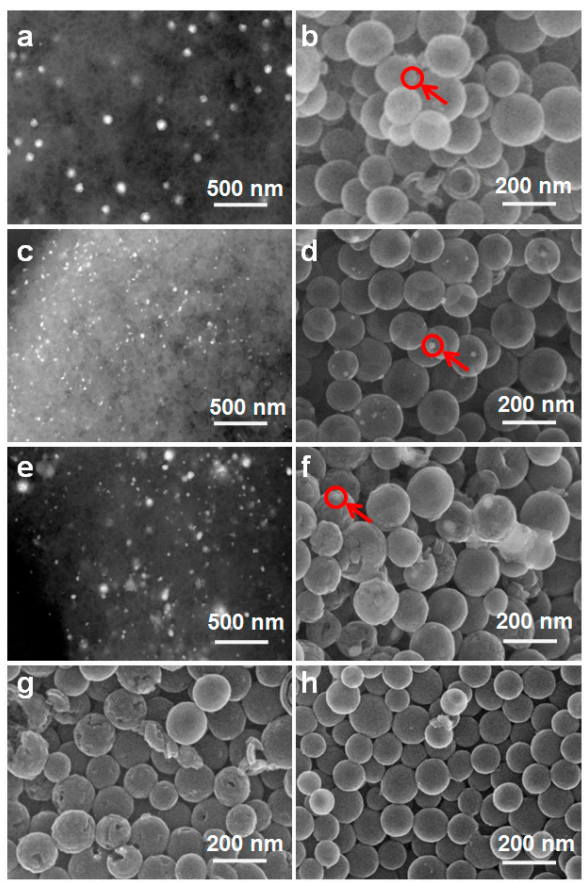

Figure 1. Back-scattering electron SEM images of (a) CoNHCS-750, (c) CoNHCS-900, and (e) CoNHCS-1050, respectively. The white dots are Co particles. SEM images of (b) CoNHCS-750, (d) CoNHCS-900, (f) CoNHCS-1050, (g) CoHCS-900, and (h) NHCS-900, respectively. The red circles show the Co particles on the surface of carbon spheres.

The X-ray diffraction studies of the CoNHCSs, CoHCSs-900, and NHCSs samples were obtained for establishing the nature of the carbon and the Co active species. The XRD patterns of the samples display two broad diffraction peaks at $25^{\circ}$ and $44^{\circ}$, which can be indexed to carbon (002) and (101) diffractions, respectively (Figure 2). The crystalline structure can be identified as alpha-Co with three crystal planes including (111), (200), and (220), among Co-containing samples. For three CoNHCS samples, the peak intensity of Co gradually increases with the treatment temperature. Additionally, with Co doping, CoNHCS-900 and CoNHCS-1050 show an increased graphite (002) peak, indicating the increased graphitization degree. During the heating process of $\mathrm{CoCl}_{2}$ and $\mathrm{NHCSs}$, the $\mathrm{CoCl}_{2}$ loses lots of crystalliferous water at $110^{\circ} \mathrm{C}$ and it reacts with carbon to form a Co substance when the temperature is above $400{ }^{\circ} \mathrm{C}$. The catalysis of Co promotes the transformation of carbon spheres from amorphous to graphitic carbon. This phenomenon was explained by a dissolving-precipitating mechanism, which means that carbon can be solved with catalysts and part of the amorphous carbon changes to graphitic carbon [33].

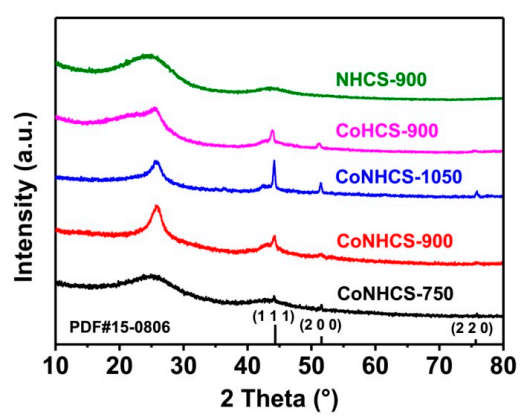

Figure 2. Powder XRD patterns of CoNHCSs at different temperatures and reference samples [Co $($ JAPDS $=15-0806)]$. 
To understand the impacts of the embedded Co in the NHCS catalysts, an X-ray photoelectron spectroscopic (XPS) analysis was conducted. The XPS measurement shows the chemical states of $\mathrm{C}, \mathrm{N}, \mathrm{O}$, and $\mathrm{Co}$ in the samples. In Figure $3 \mathrm{a}$, the $\mathrm{C}, \mathrm{N}, \mathrm{O}$, and Co peaks can be seen clearly for all CoNHCS samples. All CoNHCS samples show dominant narrow $\mathrm{C} 1 \mathrm{~s}$, weak $\mathrm{O} 1 \mathrm{~s}, \mathrm{~N} 1 \mathrm{~s}$, and $\mathrm{Co} 2 \mathrm{p}$ peaks at 284, 531, 400, and $786 \mathrm{eV}$, respectively [34-36]. For comparison, we also synthesized the CoHCS-900 by using the same treatment without $\mathrm{NH}_{3}$ dissociation and NHCS-900 without adding Co. There are no peaks of Co for NHCS-900 and no peaks of N for CoHCS-900. In addition, the elemental compositions of CoNHCSs, CoHCS-900, and NHCS-900 determined by XPS analysis are listed in Table 1. The content of $\mathrm{N}$ and Co both decreased with the increase of temperature, because there is no decomposition of $\mathrm{CoCl}_{2}$ but a small amount of volatilization of $\mathrm{N}$ via nitrogen-based gas. nitrogen-doped into carbon can be considered as n-type doping. It contributes to electrocatalytic activity because $\mathrm{N}$ can regulate the distribution of electrons and manufacture defects in the carbon materials. Nitrogen can be divided into four bounding configurations as pyridinic $\mathrm{N}(398.3 \mathrm{eV})$, pyrrolic $\mathrm{N}(400.2 \mathrm{eV})$, graphitic $\mathrm{N}(401.1 \mathrm{eV})$, and oxidized $\mathrm{N}(402.2 \mathrm{eV})[37,38]$, as shown in Figure $3 \mathrm{~b}-\mathrm{e}$. And the relative contents of four kinds of nitrogen functional groups are listed in Table 2. Previous studies suggest that both pyridinic $\mathrm{N}$ and graphitic $\mathrm{N}$ sites might have equally key roles for ORR owing to the interconvertion between them during the ORR [39]. The high-resolution $\mathrm{N} 1 \mathrm{~s}$ XPS spectra of CoNHCSs and NHCS-900 at different temperatures were analysed, as shown in Figure $3 \mathrm{~b}-\mathrm{e}$. The different kinds of $\mathrm{N}$ contents are listed in Figure 3f, in which the graphitic $\mathrm{N}$ for CoNHCS-900 accounts for the highest content. This could be caused by the existence of Co nanoparticles, which influence the bounding configurations of $\mathrm{N}$.
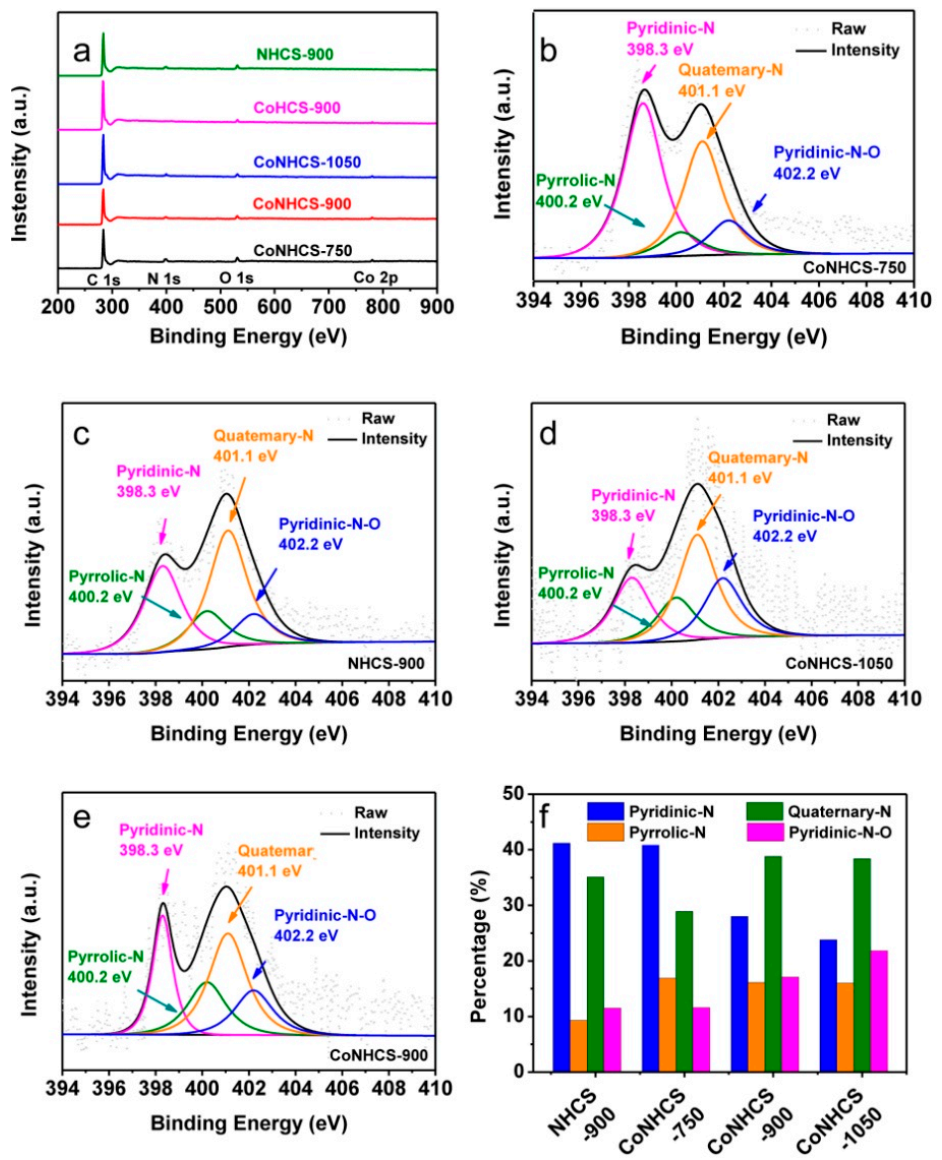

Figure 3. (a) XPS spectra of CoNHCSs and control samples, (b-e) high-resolution N 1s XPS spectra of CoNHCSs at different temperatures and (f) the relative percentage (\%) of four $\mathrm{N}$ functional species obtained from the deconvoluted N 1s XPS peaks. 
Table 1. Elemental composition of NHCSs and CoNHCSs determined by XPS analysis.

\begin{tabular}{cccccc}
\hline Samples & Carbon (at.\%) & Nitrogen (at.\%) & Oxygen (at.\%) & Cobalt (at.\%) & N/C Molar Ratio \\
\hline CoNHCS-750 & 88.0 & 6.6 & 4.9 & 0.5 & 0.075 \\
CoNHCS-900 & 91.7 & 3.8 & 4.1 & 0.4 & 0.041 \\
CoNHCS-1050 & 94.6 & 2.1 & 3.0 & 0.3 & 0.022 \\
CoHCS-900 & 96.0 & 0 & 3.8 & 0.2 & - \\
NHCS-900 & 91.0 & 4.5 & 4.5 & 0 & 0.049 \\
\hline
\end{tabular}

Table 2. The peak position and relative composition of different nitrogen groups obtained from the $\mathrm{N}$ 1s signal.

\begin{tabular}{|c|c|c|c|c|c|c|c|c|}
\hline \multirow[b]{2}{*}{ Sample } & \multicolumn{2}{|c|}{ Pyridine-N } & \multicolumn{2}{|c|}{ Pyrrolic-N } & \multicolumn{2}{|c|}{ Quaternary-N } & \multicolumn{2}{|c|}{ Pyridine-N-O } \\
\hline & $\begin{array}{c}\text { Peak Position } \\
(\mathrm{eV})\end{array}$ & at. $\%$ & $\begin{array}{c}\text { Peak Position } \\
(\mathrm{eV})\end{array}$ & at. $\%$ & $\begin{array}{c}\text { Peak Position } \\
(\mathrm{eV})\end{array}$ & at. $\%$ & $\begin{array}{c}\text { Peak Position } \\
(\mathrm{eV})\end{array}$ & at. $\%$ \\
\hline NHCS-900 & 398.3 & 44.1 & 400.2 & 9.3 & 401.1 & 35.1 & 402.2 & 11.5 \\
\hline CoNHCS-750 & 398.3 & 42.6 & 400.2 & 16.9 & 401.1 & 28.9 & 402.2 & 11.6 \\
\hline CoNHCS-900 & 398.3 & 28 & 400.2 & 16.1 & 401.1 & 38.8 & 402.2 & 17.1 \\
\hline CoNHCS-1050 & 398.3 & 23.8 & 400.2 & 16 & 401.1 & 38.4 & 402.2 & 21.8 \\
\hline
\end{tabular}

The high-resolution spectra of Co for CoNHCSs and CoHCS-900 were analysed, as shown in Figure S3. The peaks at about 778.3 and $793.3 \mathrm{eV}$ can be assigned to metallic states of cobalt, while these peaks at 780.7 and $796.5 \mathrm{eV}$ and their respective satellites at 786.8 and $803.5 \mathrm{eV}$ correspond to the binding energies of $\operatorname{Co} 2 \mathrm{p}^{3 / 2}$ and $\operatorname{Co} 2 \mathrm{p}^{1 / 2}$ of the oxide phase of the cobalt, respectively $[40,41]$. Therefore, the Co element mainly exists in the form of $\mathrm{Co}-\mathrm{N}$ and Co particles.

The highly mesoporous nature of CoNHCSs was further confirmed by the BET measurement [42]. The BET isotherm derived from nitrogen at $77 \mathrm{~K}$ shows that the total surface area of Co-doped carbon materials increases gradually, which is considerably less than that of the control sample NHCS without Co. The total surface area reaches $582 \mathrm{~m}^{2} \mathrm{~g}^{-1}$ for CoNHCS-900 (Figure 4a). Similarly, the total pore volumes at $\mathrm{P} / \mathrm{P}_{0}$ of 0.99 for all samples are listed in Table 3. The volume of CoNHCS-900 reached the maximum value. Besides, the adsorption isotherm and pore size analysis of CoNHCSs, CoHCS-900, and NHCSs (Figure 4b) demonstrate the predominant presence of wide micropores and mesopores [43-45]. Compared with CoNHCS-900, CoHCS-900 shows a smaller surface area and volume. This means that the addition of $\mathrm{N}$ improves the structure of materials, thus increasing the surface area and pore volume. According to the classification criteria formulated by the International Union of Pure and Applied Chemistry (IUPAC), the pores of carbon materials can be divided into micropores, mesopores, and macropores, of which the mesopores $(2-50 \mathrm{~nm})$ have a large specific surface area and a suitable pore volume. The pore size distribution is uniform and continuously adjustable in the range of micropores and mesopores. For these samples, there are high-density N/C active centers produced from the ammonia dissociation and Co has been considered as part of the catalytic site. Thus, CoNHCSs are potential candidates as ORR electrocatalysts.

Table 3. Specific surface area and pore structure of the CoNHCS-750, CoNHCS-900, CoNHCS-1050, CoHCS-900, and NHCS-900.

\begin{tabular}{cccc}
\hline Sample & $\left.\mathbf{S}_{\text {BET }}{ }^{\mathbf{a}} \mathbf{( m}^{\mathbf{2}} \cdot \mathbf{g}^{-\mathbf{1}}\right)$ & $\mathbf{V}_{\text {total }} \mathbf{b}\left(\mathbf{c m}^{\mathbf{3}} \cdot \mathbf{g}^{-\mathbf{1}}\right)$ & Pore Size $^{\mathbf{c}}(\mathbf{n m})$ \\
\hline CoNHCS-750 & 617 & 1.11 & $2.0,20 \sim 40$ \\
CoNHCS-900 & 582 & 1.86 & $1.7,20 \sim 40$ \\
CoNHCS-1050 & 522 & 1.50 & $1.9,20 \sim 40$ \\
CoHCS-900 & 436 & 1.27 & $1.9,20 \sim 40$ \\
NHCS-950 & 805 & 1.31 & $1.9,20 \sim 40$ \\
\hline
\end{tabular}

a Determined by the BET method at $\mathrm{P} / \mathrm{P}_{0}$ of $0.05-0.15 .{ }^{\mathrm{b}}$ Total pore volume for pores at $\mathrm{P} / \mathrm{P}_{0}$ of $0.99 .{ }^{\mathrm{c}}$ Determined by the $\mathrm{BJH}$ method from the adsorption branch. 

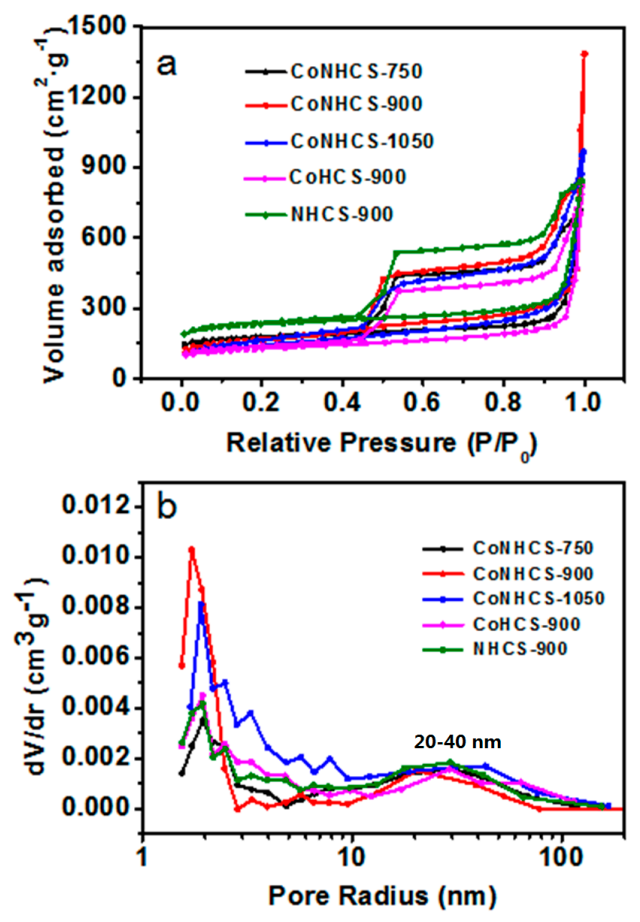

Figure 4. (a) $\mathrm{N}_{2}$ adsorption-desorption isotherms of samples and (b) the pore size distribution curves of samples.

Raman spectroscopy was used to confirm the structure information and the degree of the graphitization on the samples [46]. Raman spectra for carbon materials are shown for comparative purposes (Figure 5). The D band ranging from 1200 to $1450 \mathrm{~cm}^{-1}$ stands for defect and the G band ranging from 1500 to $1600 \mathrm{~cm}^{-1}$ represents the crystallization degree of the sp $\mathrm{sp}^{2}$ hybrid carbon atoms $[47,48]$. The carbonization of the samples was implied by $\mathrm{I}_{\mathrm{D}} / \mathrm{I}_{\mathrm{G}}$ for all samples where the $\mathrm{D}$ and $\mathrm{G}$ bands can be obviously seen at 1346 and $1590 \mathrm{~cm}^{-1}$, respectively. Besides, the ratios of the $\mathrm{I}_{\mathrm{D}} / \mathrm{I}_{\mathrm{G}}$ are $1.02,1.06$, and 1.07 for CoNHCSs which were prepared at 750,900 , and $1050{ }^{\circ} \mathrm{C}$, while 1.04 for CoHCS-900, and 1.03 for NHCS-900, respectively. That is, as the temperature increases gradually from 750 to $1050{ }^{\circ} \mathrm{C}$, the ratio of $\mathrm{I}_{\mathrm{D}} / \mathrm{I}_{\mathrm{G}}$ increases slightly, indicating that the increasing temperature introduces more defects [49]. The introduction of two elements (Co and N) can initiate a lower graphitization degree and many more defects, as demonstrated by the $\mathrm{I}_{\mathrm{D}} / \mathrm{I}_{\mathrm{G}}$ ratio of CoNHCS-900, CoHCS-900, and NHCS-900. It was reported that the increased defects can promote the oxygen reduction reaction [50].

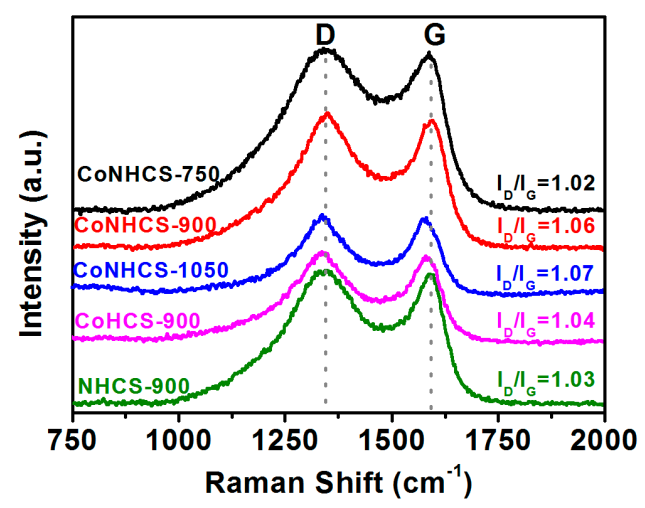

Figure 5. Raman spectra of NHCS-900, CoHCS-900, and CoNHCSs prepared at different temperatures. 
To evaluate the catalytic performance, all samples were examined by using a three-electrode system in an $\mathrm{O}_{2}$ or a $\mathrm{N}_{2}$-saturated $0.1 \mathrm{M} \mathrm{KOH}$ solution [51]. The electrocatalytic ORR performances of CoNHCSs were measured using the rotating disk electrode (RDE) method after activation by cyclic voltammograms. For comparison, the ORR properties of CoHCS-900 and NHCS-900 were also evaluated to obtain the effect of $\mathrm{N}$ and Co individually. Figure S4a shows the CVs of CoNHCSs, $\mathrm{N}$-free CoHCSs, and NHCS catalysts in an $\mathrm{O}_{2}$-saturated $0.1 \mathrm{M} \mathrm{KOH}$ solution between -0.1 to $1.2 \mathrm{~V}$ (vs. RHE). The cathodic peaks of the CoNHCSs-900 are more positive than those of the NHCS-900 $(0.715 \mathrm{~V})$ and CoHCS-900 (0.635 V). The potential histograms (Figure S4b) of the cathodic peaks indicate the apparent ORR activity of the samples and the CoNHCS-900 owns the best ORR activity among the series. Whereas only featureless double-layer charging currents for CoNHCS-900 were observed in $\mathrm{N}_{2}$-saturated $0.1 \mathrm{M} \mathrm{KOH}$ within -0.1 to $1.2 \mathrm{~V}$ (vs. RHE), there is a clear cathodic peak that appears at $0.8 \mathrm{~V}$ (Figure 6a) when the solution was saturated with $\mathrm{O}_{2}$.
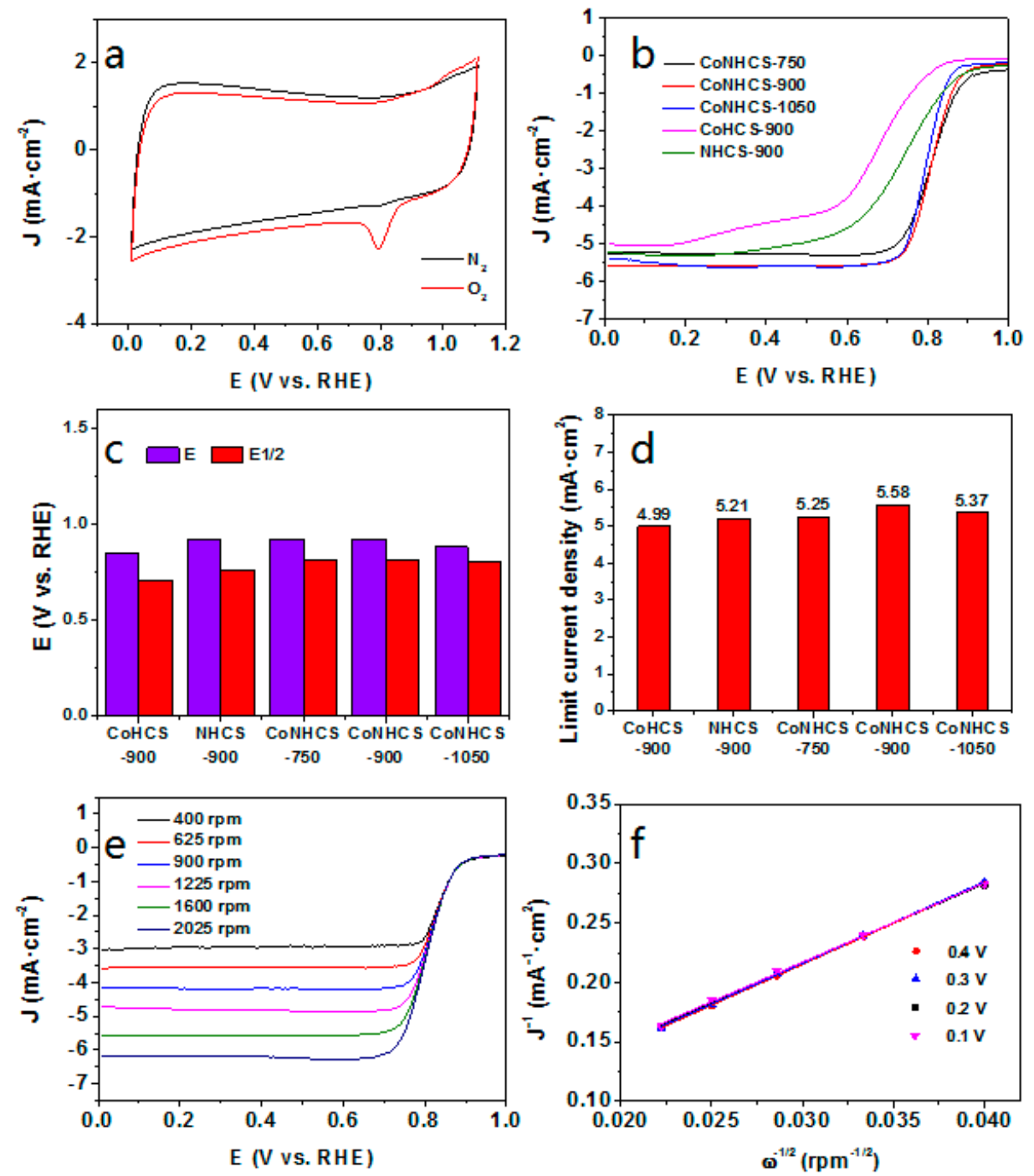

Figure 6. (a) The CV curves of the CoNHCS-900 in $\mathrm{O}_{2}$ and $\mathrm{N}_{2}$-saturated $0.1 \mathrm{M} \mathrm{KOH}$ solution; (b) LSVs of CoNHCSs at different temperatures, CoHCS-900, NHCS-900, and commercial Pt/C in $\mathrm{O}_{2}$-saturated $0.1 \mathrm{M} \mathrm{KOH}$ solution at a rotation rate of $1600 \mathrm{rpm}$; (c) the onset and half-wave potential of samples; (d) the limit current density of samples at $0 \mathrm{~V}$ (vs. RHE) in $\mathrm{O}_{2}$-saturated $0.1 \mathrm{M} \mathrm{KOH}$ solution at a rotation rate of $1600 \mathrm{rpm}$; (e) LSVs for the ORR using CoNHCS-900 in $\mathrm{O}_{2}$-saturated $0.1 \mathrm{M} \mathrm{KOH}$ solution at different rates; (f) K-L plots based on the LSVs curves of CoNHCS-900. 
The ORR performance of different samples was further researched by linear sweep voltammetry (LSV) in $0.1 \mathrm{M} \mathrm{KOH}$ in the $\mathrm{O}_{2}$-saturated at the rotating speed of $1600 \mathrm{rpm}$, as shown in Figure $6 \mathrm{~b}$. For CoNHCS-900, the onset potential is close to that of CoNHCS-750 and better than CoNHCS-1050, so is half-wave potential. Moreover, CoNHCS-900 exhibits the highest limiting current density, which is comparable to the previously reported values of Co-doped carbon materials in the literature, for instance, Co-N-CDC [33], Co/carbon nanotubes [52], and Co-doped carbon microspheres [53]. A more positive onset potential and larger limiting current density are needed for ORR in catalysts. The specific parameters of $\mathrm{E}_{\text {onset }}, \mathrm{E}_{1 / 2}$, and the limiting current density were plotted as a histogram in Figure $6 c, d$, respectively. This indicates that $900{ }^{\circ} \mathrm{C}$ is the best heat-treated temperature for Co-embedded carbon materials. A higher treatment temperature may destroy the hollow carbon spheres' structure so that the surface area and active sites with Co-N-C are affected. In contrast, a lower temperature makes it difficult to form enough active sites. The result conforms to the results obtained from BET and XPS.

In order to study the dominant factors for the catalytic activity of CoNHCSs, the results of CoHCS-900 and NHCS-900 were compared. Obviously, N-free carbon material demonstrates the poorest potential and limiting current density for ORR among the samples, while NHCS-900 had a similar onset potential and inferior limiting current density compared with CoNHCSs. Notably, it coincides with the highest total concentrations of pyridinic and graphitic nitrogen in the hollow carbon sphere (Figure 3f), although it has the low N content (2.1-6.6\%). This suggests that the ORR activity relating to onset potential was most likely determined by both nitrogen species [54,55]. Besides, the Co-N-C activity sites are favorable for the current density. In this work, the result relating to the superior ORR activity of CoNCHS-900 can be attributed to the large surface and exposure of active sites. Meanwhile, the embedded Co nanoparticles in carbon materials are good for the electron transfer as well as the electrical conductivity. LSV curves of all the samples at the rotation speeds ranging from 400 to $2050 \mathrm{rpm}$ were also collected at the sweep rate $10 \mathrm{mV} \mathrm{s}^{-1}$ (Figure 6e and Figure S5). The current density of the LSV curves at $0 \mathrm{~V}$ increases gradually with the increasing rotating speed, which can be ascribed to the fast diffusion. The exact electron transfer number (n) can be calculated based on the LSV data according to the Koutecky-Levich (K-L) equation (Equations (2) and $(3))[56,57]$. The results were then analyzed to gain further insights into the ORR kinetics [56,57]. The $n$ value of the samples obtained from Figure 6e was calculated to be 3.78-3.94 for CoNHCS-900 at potentials from 0.1 to $0.4 \mathrm{~V}$ (vs. RHE), signifying that CoNHCS-900 shows a nearly $4 \mathrm{e}^{-}$transfer pathway for the ORR. The resulting CoNHCS-900 shows a superior limiting current density to those Co-containing porous carbon spheres (Table S1).

The rotating ring-disk electrode (RRDE) experiments were also performed to further verify the ORR pathways of the samples. Figure 7a,b show the disk current and ring current of all samples, as well as commercial $\mathrm{Pt} / \mathrm{C}$ in the $\mathrm{O}_{2}$-saturated $0.1 \mathrm{M} \mathrm{KOH}$ at the rotation rate of $1600 \mathrm{rpm}$, respectively. In terms of the disk current density, CoNCHS-900 shows inferior half-wave potential $\mathrm{E}_{1 / 2}$ to $\mathrm{Pt} / \mathrm{C}$ by $55 \mathrm{mV}$, but is better than some materials obtained by other modification methods [58,59]. Firstly, the transferred electron numbers (n) were calculated by the disk and ring currents by Equation (4) and depicted in Figure 7c. The $\mathrm{n}$ of CoNHCS-900 at a potential range from 0.2 to $0.8 \mathrm{~V}$ (vs. RHE) is 3.63-3.92, which is close to that of $\mathrm{Pt} / \mathrm{C}$ and similar to the result of K-L plots. This indicates that ORR proceeded through a nearly four-electron pathway, while CoNHCS-900 is slightly better than the rest of the samples.

The $\mathrm{n}$ of CoNHCS-750, CoNHCS-1050, CoHCS-900, NHCS-900, and Pt/C is 3.73-3.90, 3.72-3.90, 2.76-3.51, 3.12-3.54, and 3.77-3.93, respectively. The measured $\mathrm{H}_{2} \mathrm{O}_{2}$ yield of CoNHCS-900 according to Equation 5, is $4.30-14.11 \%$ over the potential ranging from 0.2 to $0.8 \mathrm{~V}$ (vs. RHE), which is close to that of $\mathrm{Pt} / \mathrm{C}(3.58-8.63 \%)$ and is lower than those of CoNCHS-750 (4.30-18.57\%), CoNHCS-1050 (8.56-14.11\%), CoHCS-900 (24.80-62.19\%), and NHCS-900 (23.29-43.90\%). These results further confirm that CoNCHS-900 is an efficient electrocatalyst for ORR. 

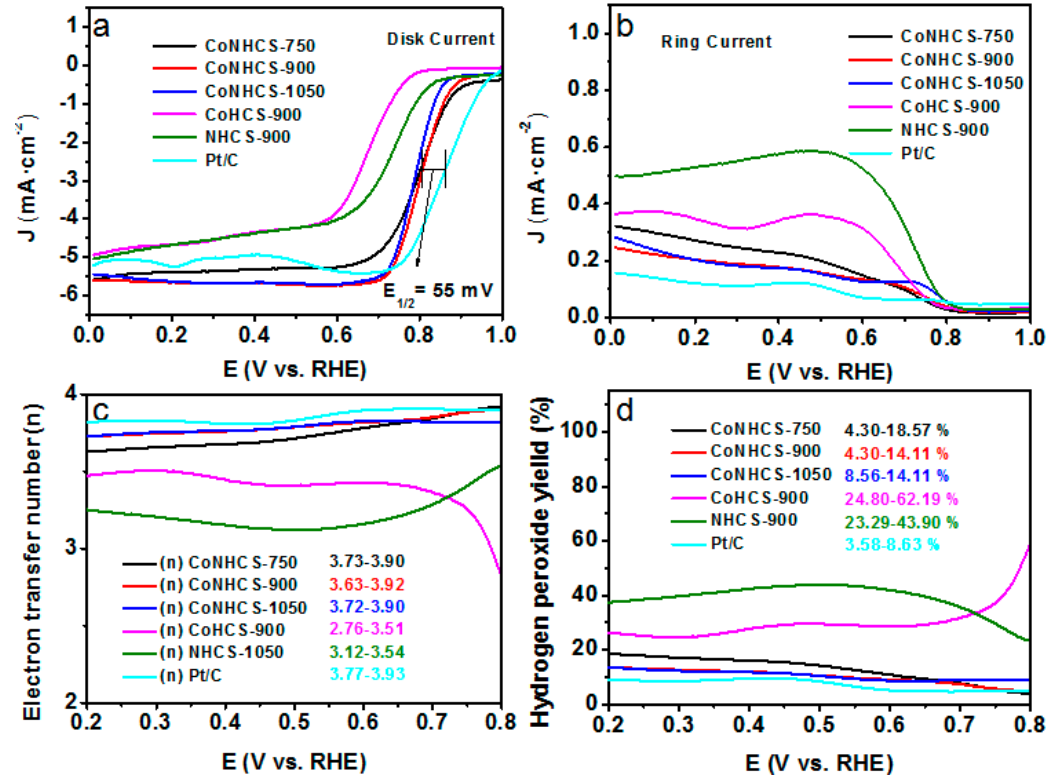

Figure 7. (a,b) LSVs on the RRDE for all samples and commercial $\mathrm{Pt} / \mathrm{C}$ in $\mathrm{O}_{2}$-saturated $0.1 \mathrm{M}$ $\mathrm{KOH}$ solution at a rotation rate of $1600 \mathrm{rpm}$. The ring potential was held at $1.2 \mathrm{~V}$ (vs. RHE), (a) disk currents and (b) ring current; (c) the calculated number of transferred electrons (n) based on the corresponding RRDE data in $(\mathbf{a}, \mathbf{b})$; $(\mathbf{d})$ the determined peroxide percentage over various potentials based on the corresponding RRDE data in $(\mathbf{a}, \mathbf{b})$.

The long-term stability and tolerance to the crossover effect of the ORR electrocatalysts are also significant parameters in practical applications in fuel cells. The choronamperometric measurement was recorded after 20,000 s in the $\mathrm{O}_{2}$-saturated $0.1 \mathrm{M} \mathrm{KOH}$ at $0.4 \mathrm{~V}$ (vs. RHE) at a rotating speed of $1600 \mathrm{rpm}$ (Figure 8a). A clear decrease for Pt/C in current density was observed after less than $1 \mathrm{~h}$. Additionally, there is $74.2 \%$ current retention at $20,000 \mathrm{~s}$, while the current retention of CoNHCS-900 is $90.2 \%$, which is much better than that of $\mathrm{Pt} / \mathrm{C}$, suggesting the excellent stability of the ORR in alkaline. The difference also manifests in the anti-methanol test after about $1000 \mathrm{~s}$ at $0.4 \mathrm{~V}$ (vs. RHE) in an $\mathrm{O}_{2}$-saturated $0.1 \mathrm{M} \mathrm{KOH}$ while adding $3 \mathrm{M}$ methanol at $200 \mathrm{~s}$. The current of $\mathrm{Pt} / \mathrm{C}$ decreases sharply when the methanol is added into the cell at $200 \mathrm{~s}$. However, there is no obvious change in the current density for the CoNHCS-900. In the end, the current density of CoNHCS-900 can remain at about $82.5 \%$, which is much higher than that of $\mathrm{Pt} / \mathrm{C}(60.4 \%)$. This indicates the strong tolerance of CoNHCS-900 to the methanol poisoning effect.
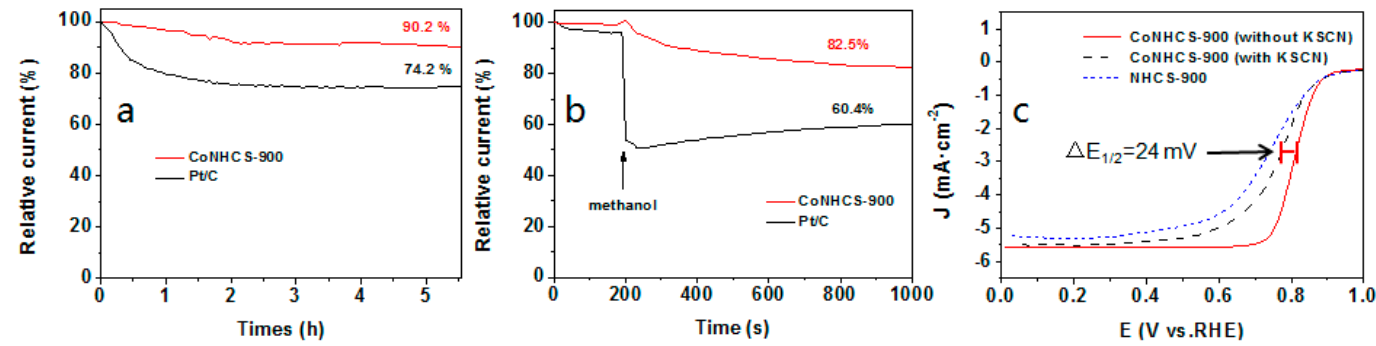

Figure 8. (a) Current-time (i-t) chronoamperometric response for the ORR on synthesized CoNHCS-900 and commercial $\mathrm{Pt} / \mathrm{C}$ in $\mathrm{O}_{2}$-saturated $0.1 \mathrm{M} \mathrm{KOH}$ at $0.4 \mathrm{~V}$ (vs. RHE) at a rotating speed of $1600 \mathrm{rpm}$. (b) Chronoamperometric curves withCoNHCS-900 and commercial Pt/C at $0.4 \mathrm{~V}$ (vs. RHE) in an $\mathrm{O}_{2}$-saturated of $0.1 \mathrm{M} \mathrm{KOH}$ while added $3 \mathrm{M}$ methanol at $200 \mathrm{~s}$. (c) LSV curves of CoNHCS-900 in $\mathrm{O}_{2}$-saturated $0.1 \mathrm{M} \mathrm{KOH}$ at a rotating speed of $1600 \mathrm{rpm}$ with and without KSCN. 
In order to investigate the effect of $\mathrm{Co}$, a $\mathrm{KSCN}$ poisoning experiment was performed. $\mathrm{SCN}^{-}$ions can combine with $\mathrm{Co}^{2+}$ and thus the catalyst could lose the activity to some degree. But $\mathrm{SCN}^{-}$ions cannot affect Co particles. By comparing the LSV curves with and without $\mathrm{KSCN}$ in $\mathrm{O}_{2}$-saturated $0.1 \mathrm{M}$ $\mathrm{KOH}$ at a rotating speed of $1600 \mathrm{rpm}$, it can be observed that a lower $\mathrm{E}_{\text {onset }}$ and $\mathrm{E}_{1 / 2}\left(\Delta \mathrm{E}_{1 / 2}=24 \mathrm{mV}\right)$ was observed in $\mathrm{KSCN} / \mathrm{KOH}$ solution. However, the half-wave potential is still more positive than that of NHCS-900, indicating that the Co nanoparticles also play an important role in improving the activity. These results clearly demonstrate that the active sites of CoNHCS-900 could be attributed to synergistic effects of the $\mathrm{N}$ doping, Co-N textures, and Co particles in the CoNCHS-900.

\section{Conclusions}

In summary, the carbon-based materials with embedded Co nanoparticles of about 0.4 at.\% were synthesized by synergistically combining Co nanoparticles with nitrogen-doped hollow carbon spheres. CoNHCS-900 demonstrates the best electrocatalytic activity towards the ORR among all the as-prepared samples in the alkaline electrolyte. Compared to commercial $\mathrm{Pt} / \mathrm{C}$, the difference in the half-wave potential is only $55 \mathrm{mV}$, while the stability after $20,000 \mathrm{~s}$ and the resistance to methanol are much better than those of $\mathrm{Pt} / \mathrm{C}$. Based on the composition characterization and electrochemical measurements, the activity sites of CoNHCS- 900 can be assigned to $\mathrm{Co}-\mathrm{N}_{\mathrm{x}}, \mathrm{Co}$ nanoparticles, and N-C. The syngeneic effects among them highly improved the electro catalytic activity of CoNHCS-900, making it a promising candidate as an electrocatalyst for fuel cells.

Supplementary Materials: The following are available online at www.mdpi.com/2311-5629/4/1/11/s1, Figure S1: TEM images of CoNHCS-900 catalyst; Figure S2: Particle size distribution of (a) CoNHCS-750, (b) CoNHCS-1050, (c) CoHCS-900, (d) CoHCS-900, (e) NHCS-900 and (f) is the mean particle diameter of samples; Figure S3: XPS spectra of Co 2P for CoNHCSs at different temperatures; Figure S4: (a) Cyclic voltammograms $(\mathrm{CVs})$ recorded at room temperature in $\mathrm{O}_{2}$-saturated in $0.1 \mathrm{KOH}$ solution with a sweep rate of $200 \mathrm{mV} \mathrm{s}^{-1}$. (b) The potentials histogram of oxidation peak for catalysts; Figure S5: LSVs for the ORR using the (a) CoNHCS-750, (b) CoNHCS-1050, (c) CoHCS-900, (d) NHCS-900 in $\mathrm{O}_{2}$-saturated $0.1 \mathrm{M} \mathrm{KOH}$ solution at different rotation rates ranging from 400 to $2025 \mathrm{rpm}$; Table S1: The comparison for the electrochemical ORR performances of various Co-containing nitrogen-doped carbon spheres.

Acknowledgments: The authors thank the financial support from the National Key Research and Development Program of China (2016YFB0700204), NSFC (51502327, 51602332), Science and Technology Commission of Shanghai Municipality (15520720400, 15YF1413800, and 16DZ2260603), Key Project for Young Researcher of State Key Laboratory of High Performance Ceramics and Superfine Microstructure, and One Hundred Talent Plan of Chinese Academy of Sciences. Minghui Yang would like to thank the National "Thousand Youth Talents" program of China.

Author Contributions: Ruohao Xing and Yao Zhou performed the experiments; Ruguang Ma and Jun Luo analyzed the data; Qian Liu, Minghui Yang and Jiacheng Wang wrote the paper. All authors reviewed the manuscript prior to submission.

Conflicts of Interest: The authors declare no conflict of interest.

\section{References}

1. Chaudhari, K.N.; Song, M.Y.; Yu, J.S. Transforming Hair into Heteroatom-Doped Carbon with High Surface Area. Small 2014, 10, 2625-2636. [CrossRef] [PubMed]

2. Gröger, O.; Gasteiger, H.A.; Suchsland, J.P. Review-Electromobility: Batteries or Fuel Cells? J. Electrochem. Soc. 2015, 162, A2605-A2622. [CrossRef]

3. Razmjooei, F.; Singh, K.P.; Bae, E.J.; Yu, J.-S. A new class electroactive Fe and P-functionalized graphene for oxygen reduction. J. Mater. Chem. A 2015, 3, 11031-11039. [CrossRef]

4. Siebel, A.; Gorlin, Y.; Durst, J.; Proux, O.; Hasché, F.; Tromp, M.; Gasteiger, H.A. Identification of Catalyst Structure during the Hydrogen Oxidation Reaction in an Operating PEM Fuel Cell. ACS Catal. 2016. [CrossRef]

5. Song, M.Y.; Park, H.Y.; Yang, D.-S.; Bhattacharjya, D.; Yu, J.-S. Back Cover: Seaweed-Derived Heteroatom-Doped Highly Porous Carbon as an Electrocatalyst for the Oxygen Reduction Reaction (ChemSusChem 6/2014). Chemsuschem 2014, 7, 1755-1763. [CrossRef] [PubMed] 
6. Ge, X.; Sumboja, A.; Wuu, D.; An, T.; Li, B.; Goh, F.W.T.; Hor, T.S.A.; Zong, Y.; Liu, Z. Oxygen Reduction in Alkaline Media: From Mechanisms to Recent Advances of Catalysts. ACS Catal. 2015, 5, 4643-4667. [CrossRef]

7. Gasteiger, H.A.; Kocha, S.S.; Sompalli, B.; Wagner, F.T. Activity Benchmarks for Pt, Pt-alloy and non-Pt oxygen reduction catalysts for PEMFCs. Appl. Catal. B Environ. 2005, 56, 9-35. [CrossRef]

8. Wu, G.; Zelenay, P. Nanostructured nonprecious metal catalysts for oxygen reduction reaction. Acc. Chem. Res. 2013, 46, 1878-1889. [CrossRef] [PubMed]

9. Bezerra, C.W.B.; Zhang, L.; Lee, K.; Liu, H.; Marques, A.L.B.; Marques, E.P.; Wang, H.; Zhang, J. A review of Fe-N/C and Co-N/C catalysts for the oxygen reduction reaction. Electrochim. Acta 2008, 53, 4937-4951. [CrossRef]

10. Gu, D.; Ma, R.; Zhou, Y.; Wang, F.; Yan, K.; Liu, Q.; Wang, J. Synthesis of Nitrogen-Doped Porous Carbon Spheres with Improved Porosity toward the Electrocatalytic Oxygen Reduction. ACS Sustain. Chem. Eng. 2017, 5, 11105-11116. [CrossRef]

11. Zhou, T.; Zhou, Y.; Ma, R.; Zhou, Z.; Liu, G.; Liu, Q.; Zhu, Y.; Wang, J. Nitrogen-doped hollow mesoporous carbon spheres as a highly active and stable metal-free electrocatalyst for oxygen reduction. Carbon 2017, 114, 177-186. [CrossRef]

12. Hu, C.; Zhou, Y.; Ma, R.; Liu, Q.; Wang, J. Reactive template synthesis of nitrogen-doped graphene-like carbon nanosheets derived from hydroxypropyl methylcellulose and dicyandiamide as efficient oxygen reduction electrocatalysts. J. Power Sources 2017, 345, 120-130. [CrossRef]

13. Singh, K.; Razmjooei, F.; Yu, J.S. Active sites and factors influencing them for efficient oxygen reduction reaction in metal-N coordinated pyrolyzed and non-pyrolyzed catalysts: A review. J. Mater. Chem. A 2017, 5, 20095-20119. [CrossRef]

14. Lefèvre, M.; Dodelet, J.P. Fe-based electrocatalysts made with microporous pristine carbon black supports for the reduction of oxygen in PEM fuel cells. Electrochim. Acta 2008, 53, 8269-8276. [CrossRef]

15. Min, J.P.; Lee, J.H.; Hembram, K.P.S.S.; Lee, K.-R.; Han, S.S.; Yoon, C.W.; Nam, S.-W.; Kim, J.Y. Oxygen Reduction Electrocatalysts Based on Coupled Iron Nitride Nanoparticles with Nitrogen-Doped Carbon. Catalysts 2016, 6, 86. [CrossRef]

16. Sun, T.; Tian, B.; Lu, J.; Su, C. Recent Advances of Fe (or Co)/N/C Electrocatalysts for Oxygen Reduction Reaction in Polymer Electrolyte Membrane Fuel Cells. J. Mater. Chem. A 2017, 5, 18933-18950. [CrossRef]

17. Sun, T.; Wu, Q.; Che, R.; Bu, Y.; Jiang, Y.; Li, Y.; Yang, L.; Wang, X.; Hu, Z. Alloyed Co-Mo Nitride as High-Performance Electrocatalyst for Oxygen Reduction in Acidic Medium. ACS Catal. 2016, 5, 1857-1862. [CrossRef]

18. Chung, H.T.; Won, J.H.; Zelenay, P. Active and stable carbon nanotube/nanoparticle composite electrocatalyst for oxygen reduction. Nat. Commun. 2013, 4, 1922. [CrossRef] [PubMed]

19. Deng, D.; Yu, L.; Chen, X.; Wang, G.; Jin, L.; Pan, X.; Deng, J.; Sun, G.; Bao, X. Iron Encapsulated within Pod-like Carbon Nanotubes for Oxygen Reduction Reaction. Angew. Chem. 2013, 52, 371-375. [CrossRef] [PubMed]

20. Strickland, K.; Miner, E.; Jia, Q.; Tylus, U.; Ramaswamy, N.; Liang, W.; Sougrati, M.-T.; Jaouen, F.; Mukerjee, S. Highly active oxygen reduction non-platinum group metal electrocatalyst without direct metal-nitrogen coordination. Nat. Commun. 2015, 6, 7343. [CrossRef] [PubMed]

21. Yang, W.; Liu, X.; Yue, X.; Jia, J.; Guo, S. Bamboo-like carbon nanotube/Fe3C nanoparticle hybrids and their highly efficient catalysis for oxygen reduction. J. Am. Chem. Soc. 2015, 137, 1436-1439. [CrossRef] [PubMed]

22. Zhou, Y.; Wang, J. Direct Observation of Fe-N4 Species as Active Sites for the Electrocatalytic Oxygen Reduction. Nano Adv. 2017, 2, 45-46. [CrossRef]

23. Malko, D.; Kucernak, A.; Lopes, T. In situ electrochemical quantification of active sites in Fe-N/C non-precious metal catalysts. Nat. Commun. 2016, 7, 13285. [CrossRef] [PubMed]

24. Sahraie, N.R.; Kramm, U.I.; Steinberg, J.; Zhang, Y.; Thomas, A.; Reier, T.; Paraknowitsch, J.-P.; Strasser, P. Quantifying the density and utilization of active sites in non-precious metal oxygen electroreduction catalysts. Nat. Commun. 2015, 6. [CrossRef] [PubMed]

25. Tang, H.; Cai, S.; Xie, S.; Wang, Z.; Tong, Y.; Pan, M.; Lu, X. Metal-Organic-Framework-Derived Dual Metaland Nitrogen-Doped Carbon as Efficient and Robust Oxygen Reduction Reaction Catalysts for Microbial Fuel Cells. Adv. Sci. 2016, 3, 1487-1498. [CrossRef] [PubMed] 
26. Wang, Z.; Li, B.; Ge, X.; Goh, F.W.T.; Zhang, X.; Du, G.; Wuu, D.; Liu, Z.; Hor, T.S.A.; Zhang, H.; et al. $\mathrm{Co} @ \mathrm{Co}_{3} \mathrm{O}_{4} @ P P D$ Core@bishell Nanoparticle-Based Composite as an Efficient Electrocatalyst for Oxygen Reduction Reaction. Small 2016, 12, 2580-2587. [CrossRef] [PubMed]

27. Lee, K.J.; Shin, D.Y.; Byeon, A.; Lim, A.; Jo, Y.S.; Begler, A.; Lim, D.H.; Sung, Y.E.; Park, H.S.; Chae, K.H.; et al. Hierarchical cobalt-nitride and -oxide co-doped porous carbon nanostructures for highly efficient and durable bifunctional oxygen reaction electrocatalysts. Nanoscale 2017, 9, 15846-15855. [CrossRef] [PubMed]

28. Zhong, X.; Liu, L.; Jiang, Y.; Wang, X.; Wang, L.; Zhuang, G.; Li, X.; Mer, D.; Wang, J.; Su, D. Synergistic Effect of Nitrogen in Cobalt Nitride and Nitrogen-Doped Hollow Carbon Spheres for the Oxygen Reduction Reaction. Chemcatchem 2015, 7, 1826-1832. [CrossRef]

29. Zhou, T.; Zhou, Y.; Ma, R.; Zhou, Z.; Liu, G.; Liu, Q.; Zhu, Y.; Wang, J. In situ formation of nitrogen-doped carbon nanoparticles on hollow carbon spheres as efficient oxygen reduction electrocatalysts. Nanoscale 2016, 8, 18134-18142. [CrossRef] [PubMed]

30. Xiao, M.; Zhu, J.; Feng, L.; Liu, C.; Xing, W. Meso/Macroporous Nitrogen-Doped Carbon Architectures with Iron Carbide Encapsulated in Graphitic Layers as an Efficient and Robust Catalyst for the Oxygen Reduction Reaction in Both Acidic and Alkaline Solutions. Adv. Mater. 2015, 27, 2521-2527. [CrossRef] [PubMed]

31. Zhou, T.; Ma, R.; Zhou, Y.; Xing, R.; Liu, Q.; Zhu, Y.; Wang, J. Efficient N-doping of hollow core-mesoporous shelled carbon spheres via hydrothermal treatment in ammonia solution for the electrocatalytic oxygen reduction reaction. Microporous Mesoporous Mater. 2018, 261, 88-97. [CrossRef]

32. Gabe, A.; García-Aguilar, J.; Berenguer-Murcia, Á.; Morallón, E.; Cazorla-Amorós, D. Key factors improving oxygen reduction reaction activity in cobalt nanoparticles modified carbon nanotubes. Appl. Catal. B Environ. 2017, 217, 303-312. [CrossRef]

33. Ratso, S.; Kruusenberg, I.; Käärik, M.; Kook, M.; Saar, R.; Kanninen, P.; Kallio, T.; Leis, J.; Tammeveski, K. Transition metal-nitrogen co-doped carbide-derived carbon catalysts for oxygen reduction reaction in alkaline direct methanol fuel cell. Appl. Catal. B Environ. 2017, 219, 276-286. [CrossRef]

34. Liu, W.; Zhang, L.; Yan, W.; Liu, X.; Yang, X.; Miao, S.; Wang, W.; Wang, A.; Zhang, T. Single-atom dispersed Co-N-C catalyst: Structure identification and performance for hydrogenative coupling of nitroarenes. Chem. Sci. 2016, 7, 5758-5764. [CrossRef]

35. Wang, J.; Liu, Q. An Ordered Mesoporous Aluminosilicate Oxynitride Template to Prepare N-Incorporated Ordered Mesoporous Carbon. J. Phys. Chem. C 2007, 111, 7266-7272. [CrossRef]

36. Ma, R.; Zhou, Y.; Wang, F.; Yan, K.; Liu, Q.; Wang, J. Efficient electrocatalysis of hydrogen evolution by ultralow-Pt-loading bamboo-like nitrogen-doped carbon nanotubes. Mater. Today Energy 2017, 6, 173-180. [CrossRef]

37. Liu, G.; Li, X.; Ganesan, P.; Popov, B.N. Development of non-precious metal oxygen-reduction catalysts for PEM fuel cells based on N-doped ordered porous carbon. Appl. Catal. B Environ. 2009, 93, 156-165. [CrossRef]

38. Gao, R.; Zhou, Y.; Liu, X.; Wang, J. N-Doped Defective Carbon Layer Encapsulated $\mathrm{W}_{2} \mathrm{C}$ as a Multifunctional Cathode Catalyst for High Performance $\mathrm{Li}_{-} \mathrm{O}_{2}$ Battery. Electrochim. Acta 2017, 245, 430-437. [CrossRef]

39. Daems, N.; Sheng, X.; Vankelecom, I.F.J.; Pescarmona, P.P. Metal-free doped carbon materials as electrocatalysts for the oxygen reduction reaction. J. Mater. Chem. A 2014, 2, 4085-4110. [CrossRef]

40. Singh, D.; Soykal, I.I.; Tian, J.; von Deak, D.; King, J.; Miller, J.T.; Ozkan, U.S. In situ characterization of the growth of CNx carbon nano-structures as oxygen reduction reaction catalysts. J. Catal. 2013, 304, 100-111. [CrossRef]

41. Antolini, E.; Zhecheva, E. Lithiation of spinel cobalt oxide by solid state reaction of $\mathrm{Li}_{2} \mathrm{CO}_{3}$ and $\mathrm{Co}_{3} \mathrm{O}_{4}$ : An EPR study. Mater. Lett. 1998, 35, 380-382. [CrossRef]

42. Xiu, T.; Wang, J.; Liu, Q. Ordered bimodal mesoporous boria-alumina composite: One-step synthesis, structural characterization, active catalysis for methanol dehydration. Microporous Mesoporous Mater. 2011, 143, 362-367. [CrossRef]

43. Wang, J.; Liu, Q. Mesoporous silicon oxynitride thin films. Chem. Commun. 2006, 900-902. [CrossRef] [PubMed]

44. Wang, J.C.; Liu, Q. Synthesis and characterization of ordered mesoporous SiOxNy thin films with different nitrogen contents. Nanotechnology 2006, 17, 2828-2834. [CrossRef]

45. Xiu, T.P.; Liu, Q.; Wang, J.C. Alkali-free borosilicate glasses with wormhole-like mesopores. J. Mater. Chem. 2006, 16, 4022-4024. [CrossRef] 
46. Ghosh, K.; Kumar, M.; Maruyama, T.; Ando, Y. Micro-structural, electron-spectroscopic and field-emission studies of carbon nitride nanotubes grown from cage-like and linear carbon sources. Carbon 2009, 47, 1565-1575. [CrossRef]

47. Ferrari, A.C.; Robertson, J. Interpretation of Raman spectra of disordered and amorphous carbon. Phys. Rev. B Condens. Matter 2000, 61, 14095-14107. [CrossRef]

48. Yang, Q.H.; Hou, P.X.; Unno, M.; Yamauchi, S.; Saito, R.; Kyotani, T. Dual Raman features of double coaxial carbon nanotubes with N-doped and B-doped multiwalls. Nano Lett. 2005, 5, 2465-2469. [CrossRef] [PubMed]

49. Zhou, T.; Zhou, Y.; Ma, R.; Liu, Q.; Zhu, Y.; Wang, J. Achieving excellent activity and stability for oxygen reduction electrocatalysis by hollow mesoporous iron-nitrogen-doped graphitic carbon spheres. J. Mater. Chem. A 2017, 5, 12243-12251. [CrossRef]

50. Katagiri, G. Raman spectroscopy of graphite and carbon materials and its recent application. Carbon 1997, 35, 716. [CrossRef]

51. Li, P.; Ma, R.; Zhou, Y.; Chen, Y.; Zhou, Z.; Liu, G.; Liu, Q.; Peng, G.; Liang, Z.; Wang, J. In situ growth of spinel $\mathrm{CoFe}_{2} \mathrm{O}_{4}$ nanoparticles on rod-like ordered mesoporous carbon for bifunctional electrocatalysis of both oxygen reduction and oxygen evolution. J. Mater. Chem. A 2015, 3, 15598-15606. [CrossRef]

52. Zheng, Z.; Xu, B.; Huang, L.; He, L.; Ni, X. Novel composite of Co/carbon nanotubes: Synthesis, magnetism and microwave absorption properties. Solid State Sci. 2008, 10, 316-320. [CrossRef]

53. Zhou, J.; Lian, J.; Hou, L.; Zhang, J.; Gou, H.; Xia, M.; Zhao, Y.; Strobel, T.A.; Tao, L.; Gao, F. Ultrahigh volumetric capacitance and cyclic stability of fluorine and nitrogen co-doped carbon microspheres. Nat. Commun. 2015, 6, 8503. [CrossRef] [PubMed]

54. Chen, Y.; Liu, Q.; Wang, J. Carbon dioxide activated carbon nanofibers with hierarchical micro-/mesoporosity towards electrocatalytic oxygen reduction. J. Mater. Chem. A 2016, 4, 5553-5560. [CrossRef]

55. Ma, R.; Ren, X.; Xia, B.Y.; Zhou, Y.; Sun, C.; Liu, Q.; Liu, J.; Wang, J. Novel synthesis of N-doped graphene as an efficient electrocatalyst towards oxygen reduction. Nano Res. 2016, 9, 808-819. [CrossRef]

56. Ma, R.; Xia, B.Y.; Zhou, Y.; Li, P.; Chen, Y.; Liu, Q.; Wang, J. Ionic liquid-assisted synthesis of dual-doped graphene as efficient electrocatalysts for oxygen reduction. Carbon 2016, 102, 58-65. [CrossRef]

57. Zheng, Y.; Jiao, Y.; Ge, L.; Jaroniec, M.; Qiao, S.Z. Two-Step Boron and Nitrogen Doping in Graphene for Enhanced Synergistic Catalysis. Angew. Chem. 2013, 52, 3110-3116. [CrossRef] [PubMed]

58. Yu, Y.M.; Zhang, J.H.; Xiao, C.H.; Zhong, J.D.; Zhang, X.H.; Chen, J.H. High Active Hollow Nitrogen-Doped Carbon Microspheres for Oxygen Reduction in Alkaline Media. Fuel Cells 2012, 12, 506-510. [CrossRef]

59. Zheng, F.; Mu, G.; Zhang, Z.; Shen, Y.; Zhao, M.; Pang, G. Nitrogen-doped hollow macroporous carbon spheres with high electrocatalytic activity for oxygen reduction. Mater. Lett. 2012, 68, 453-456. [CrossRef] 